\title{
Contraception counselling during gynecology visit - does a questionnaire help?
}

\author{
Funda Gungor Ugurlucan $₫$, Omer Demir $₫$, Sema Tas $₫$,

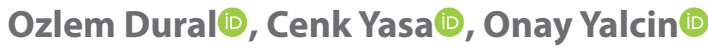 \\ Department of Obstetrics and Gynecology, Istanbul University Istanbul Faculty of Medicine, Istanbul, Turkey
}

\begin{abstract}
Objectives: Women are at risk of unplanned pregnancy and inappropriate choice of contraception if not given effective contraception counselling. We aimed to understand the contraceptive needs of women, improve effective contraception counselling promoting modern contraception methods during gynecology outpatient visit using a contraception counselling questionnaire.

Material and methods: All reproductive-age women over 18 were given Contraception Counselling Project Form to fill in while in the waiting room. The form consisted of 15 questions evaluating patients' characteristics and contraceptive method used. Physicians evaluated these forms during the examination and an appropriate method was chosen. Forms of pregnant, postmenopausal and sexually inactive patients as well as forms with more than one answer missing were excluded.

Results: 778 questionnaires were accepted for evaluation. 340 women (43.8\%) used modern contraception, 112 (14.4\%) used interrupted coitus, $3(0.4 \%)$ used calendar method. 738 women could be given adequate contraception counselling by the physicians. 215 women among 323 women (66.5\%) who did not use modern contraception and did not desire pregnancy, were convinced to use modern contraception and 103 (91.9\%) among 112 women who used interrupted coitus for contraception were convinced to use modern contraception. There was a significant relationship between age, education, working state, parity, number and type of delivery, previous OCP usage, resources of contraception and the preferred contraception method.
\end{abstract}

Conclusions: More than half the women preferred to use modern contraception methods by means of contraception counselling questionnaire. Women's backgrounds significantly affected their choice of contraception method.

Key words: contraception; contraception counselling; oral contraception; intrauterine device

Ginekologia Polska 2020; 91, 10: 582-588

\section{INTRODUCTION}

Contraception can be defined as the use of methods intended to prevent reproduction. Contraception can be categorized as modern or traditional. Modern methods of contraception include sterilization, intrauterine devices (IUD), subdermal implants, oral contraceptive pills, condoms and other barrier methods, injectable contraceptives, contraceptive patches, and vaginal rings [1]. Traditional methods of contraception include the rhythm method, withdrawal prior to ejaculation, lactational amenorrhea, and abstinence.

Contraception counselling is crucial in gynecology practice even in patients who do not apply for contraception counselling. In the outpatient clinic, time devoted for contraception counselling may be limited. Some patients express other complaints more often or physicians may concentrate on patients' complaints rather than counselling. The aims of the counselling are to educate women about contraception, select an appropriate method according to demand and preferences, prevent unintended pregnancy, and provide fertility when desired.

The American College of Obstetricians and Gynecologists advises to ask all women between ages 18-50 if pregnancy is desired over next year [2]. If pregnancy is not desired, appropriate contraception should be chosen according to state of health, personal values, and preferences. Even in countries with a high rate of contraception usage, almost $40 \%$ of women are at risk for unintended pregnancy [3]. In 2011, 45\% of pregnancies in US were unintended [4]. Most sexually active women in US had used some form of contraception in their lifetime, but multiple barriers prevented women from obtaining contraceptives or using them effectively or consistently [5]. The main reasons for imperfect use of contraception were inappropriate counselling and incorrect choices of contraception method [6]. Rates of contraceptive use throughout 
Europe are high; $90 \%$ of women in Europe have been reported as using contraception [7]. However, in Europe, $45 \%$ of pregnancies are unintended and $64 \%$ of these result in abortion [8]. Almost half of these unintended pregnancies occur as a result of incorrect or inconsistent use of contraceptives [9]. Mean age at first birth is over 30 in Europe; thus most couples must use contraception for many years in order to avoid unintended pregnancy [10]. But different models of contraception care and contraception counselling exist across Europe which may not be adequate in some cases [11].

Alkema et al reported that contraceptive prevalence in Turkey increased from $62.2 \%$ in 1990 to $72.2 \%$ in 2010 with a decrease in the unmet need for contraception from $14.7 \%$ to $8.7 \%$ [12]. Modern contraceptive prevalence was reported between $20-40 \%$ [13]. Also, $51 \%$ of all women and $74 \%$ of the married women in the reproductive years use contraception with unintended pregnancy rate of $47.3 \%$ [14]. Only $33 \%$ of all women and $47 \%$ of married women use modern contraception. This might be due to inadequate counselling given to women regarding modern contraception methods. Kahramanoglu et al evaluated the differences in contraceptive choices before and after counselling Turkish women and suggested that contraceptive counselling significantly changed the contraceptive choices of women [15]. However, few studies have been published on how to implement contraceptive counselling to women [16-20].

\section{Objectives}

Our primary aim in this study was to screen out women who needed contraception counselling before they entered physicians'room with a form that they filled out while waiting and to evaluate the results. We evaluated whether effective contraceptive counselling increased the rate of modern contraceptive method usage among women who either did not use any contraception or used interrupted coitus for contraception. Our secondary aim was to evaluate the factors such as age, education, working state, parity, number and type of delivery, previous OCP usage, resources of contraception that influenced the preferred contraception method.

\section{MATERIAL AND METHODS}

Between June-December 2016, all reproductive-age women over 18 who applied to the gynecology clinic of Istanbul University Istanbul Faculty of Medicine Department of Obstetrics and Gynecology and who were mentally capable of filling out the questionnaire were given the contraception counselling form prepared by our institution. Ethics approval was obtained from the institutional ethics committee. Forms of patients who were postmenopausal, pregnant, or sexually inactive were excluded. Other exclusion criteria were being mentally incapable of filling out the form, being illiterate and not willing to participate in study.

\begin{tabular}{|c|c|c|}
\hline \multicolumn{3}{|l|}{ Appendix 1. Contraception Counselling Form } \\
\hline \multicolumn{3}{|l|}{ 1. Age } \\
\hline \multicolumn{3}{|l|}{ 2. Last Menstrual Period } \\
\hline 3. Have you ever delivered? & Yes & No \\
\hline \multicolumn{3}{|l|}{ If your answer is yes } \\
\hline \multicolumn{3}{|l|}{ 4. How many deliveries? } \\
\hline \multicolumn{3}{|l|}{ 5. Time of last delivery? } \\
\hline \multicolumn{3}{|l|}{ 6. Are you lactating? } \\
\hline 7. Do you plan a pregnancy in the next 6 months? & Yes & No \\
\hline 8. Do you use a method to prevent pregnancy? & Yes & No \\
\hline \multicolumn{3}{|l|}{ 9. If your answer is yes, which method do you use? } \\
\hline \multicolumn{3}{|l|}{ Oral contraceptive pills } \\
\hline \multicolumn{3}{|l|}{ Intrauterine device } \\
\hline \multicolumn{3}{|l|}{ Condom } \\
\hline \multicolumn{3}{|l|}{ Interrupted coitus } \\
\hline \multicolumn{3}{|l|}{ Tubal ligation } \\
\hline \multicolumn{3}{|l|}{ Calendar method } \\
\hline $\begin{array}{l}\text { 10. Have you ever used oral contraceptive pills and } \\
\text { for how long? }\end{array}$ & Yes & No \\
\hline \multicolumn{3}{|l|}{ 11. Reason for quitting oral contraceptive pills? } \\
\hline 12. Do you smoke? & Yes & No \\
\hline \multicolumn{3}{|l|}{ 13. How long does your period last? } \\
\hline \multicolumn{3}{|l|}{ 14. Your weight and height? } \\
\hline 15. Do you have a diagnosed illness? & Yes & No \\
\hline If yes, what is it? & & \\
\hline
\end{tabular}

The contraception counselling form was formed by four gynecologists experienced in contraception counselling. The form consisted of 15 questions, including age, education, ongoing pregnancy or desire for pregnancy, parity, type of delivery, lactation, previously and currently used contraceptive method, reasons for not using contraception or changed method, sources of information regarding contraception, smoking, menstrual history, and history of diagnosed diseases (Appendix 1). Pilot testing was performed in ten women recruited from the gynecology outpatient clinic. Two experts interviewed the women after filling out the forms. There were no missing answers. The women thought that the questionnaire was applicable.

One thousand four hundred fifty-six women were recruited. The total number of women participating and the number of forms filled were 1000. Forms, which had more than one unanswered question were excluded. Forms in which the advised contraception method was not noted by the physicians were accepted as counselling not given. All participants filled out the forms by themselves in a designated private room while waiting and the patient and the physician evaluated the form in the examination room. Of the 1000 women, 87 forms were excluded because 
Table 1. Demographic variables of women included in the study

\begin{tabular}{|c|}
\hline Age \\
\hline Height \\
\hline Weight \\
\hline Parity \\
\hline Yes \\
\hline No \\
\hline
\end{tabular}

Mean number of deliveries

$\mathrm{N}=778$

$36.8 \pm 8.1(19-51)$

$161.7 \pm 6.3 \mathrm{~cm}(143-185 \mathrm{~cm})$

$68.4 \pm 13.3 \mathrm{~kg}(47-120 \mathrm{~kg})$

$609(78.3 \%)$

$169(21.8 \%)$

$2.1 \pm 1.1(1-9)$

Type of Delivery

Vaginal delivery

$293(48.1 \%)$

Cesarean section

$248(40.7 \%)$

Vaginal delivery+

Cesarean section

$68(11.2 \%)$

Education Level

Primary schoo

$293(37.7 \%)$

Middle school

$112(14.4 \%)$

High school

190 (24.4\%)

University

157 (20.2\%)

Higher degree

21 (2.7\%)

No answer

$5(0.6 \%)$

Working

Yes

286 (36.8\%)

No

492 (63.2\%)

Aware of last menstrual period

Yes

645 (82.9\%)

No

$133(17.1 \%)$

Lactation

Yes

$62(8.0 \%)$

No

$716(92.0 \%)$

Smoking

Yes

206 (26.5\%)

No

572 (73.5\%)

Plan of a pregnancy in the near

future

\begin{tabular}{|l|l|}
\hline Yes & $164(21.1 \%)$ \\
\hline No & $591(75.9 \%)$ \\
\hline No answer & $23(3.0 \%)$ \\
\hline
\end{tabular}

46 women were postmenopausal/sexually inactive, and 41 women missed out more than one question. The number of women able to fill out the questionnaires completely was 823. Sixty women missed out one question and physicians did not counsel 30 patients although they filled out the form completely. One hundred thirty-five women were currently pregnant and were excluded. As a result, 778 forms were accepted for evaluation.
Physicians performed gynecologic examination on all patients. Menstrual irregularities, pelvic pain, vaginal discharge, breast diseases, abnormal PAP-smear results were assessed. PAP-smear and ultrasonography was performed when indicated. At the end of the examination, the form was examined by the physician and contraception counselling was given to patients.

Contraception counselling included types of contraceptive methods available in Turkey, their mechanisms of action, efficacy of each method, possible side effects, risk of cancer, effects on fertility, effects on menstrual cycle, and non-contraceptive benefits. Physicians advised most preferred contraceptive methods by Turkish women. These were copper-intrauterine device (Copper-IUD), levonorgestrel-releasing intrauterine device (LNG-IUD), combined oral contraceptives (OCP), progestin only pill, condom, bilateral tubal ligation (BTL), depot medroxyprogesterone acetate. Physicians used WHO medical eligibility criteria for contraception and ACOG guidelines for counselling [2, 21, 22]. At the end of the visit, method advised was noted on the form by the physician.

\section{Statistical analysis}

Statistical analysis was performed with Statistical Package for the Social Sciences (SPSS) version 21.0 (SPSS, Chicago, IL, USA) by a professional statistician. Data was expressed as mean \pm standard deviation and frequencies. The relationship between factors that could affect choice of contraception and the contraception methods preferred by the women were analyzed using Pearson's correlation. Groups of preferred contraception methods were analyzed using Chi-square test for categorical variables and Kruskal-Wallis test for continuous dependent variables. A p value $<0.05$ was considered as statistically significant.

\section{RESULTS}

Seven hundred seventy-eight forms were accepted for evaluation. Demographic variables are summarized in Table 1. Mean age was 36.8 \pm 8.1 .609 (78.3\%) women had delivered before. Mean number of deliveries was $2.1 \pm 1.1$. $48.9 \%$ of women delivered vaginally. 286 women $(36.8 \%)$ were working. $164(21.1 \%)$ women were planning a pregnancy soon, 23 women (2.9\%) did not answer this question. 62 women (7.9\%) were lactating.

Resources that patients had received information about contraception are summarized in Figure 1. 605 women (77.8\%) recalled receiving information regarding contraception before. 399 women (65.9\%) recalled receiving information from physicians, whereas only 2 women (0.3\%) from newspapers.

Four hundred fifty-five (58.5\%) women used a contraceptive method; 340 women (43.8\%) used modern contracep- 


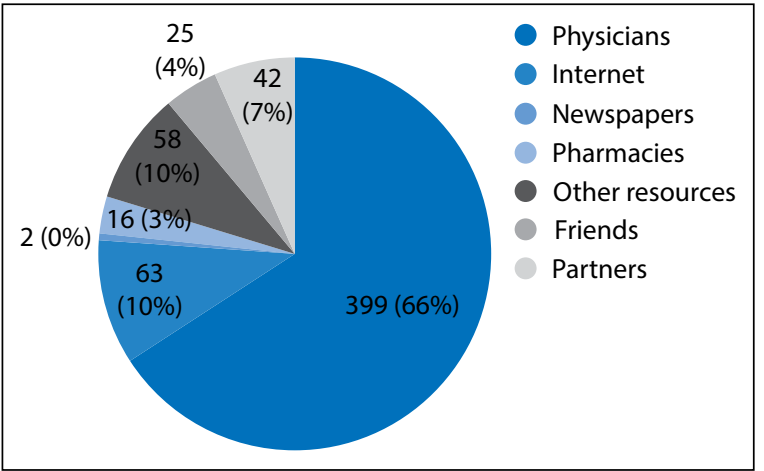

Figure 1. Distribution of resources that women had received information about contraception before

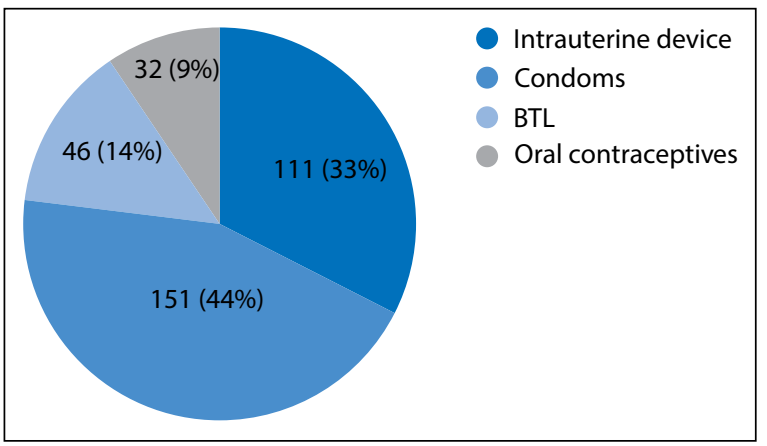

Figure 2. Distribution of contraception methods used by the women

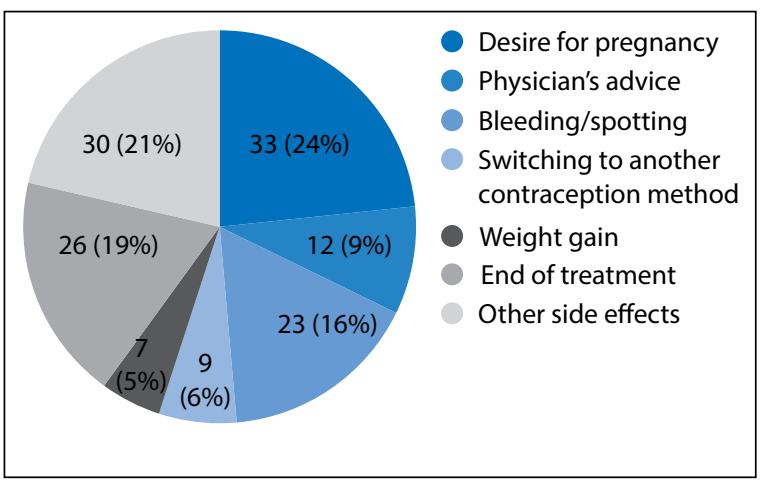

Figure 3. Reasons for stopping combined oral contraceptive usage

tive methods whereas 112 women (14.4\%) used interrupted coitus and 3 women $(0.4 \%)$ used the calendar method. The number of women that did not use any contraceptive method was 323 (41.5\%). Distribution of modern contraceptive methods is summarized in Figure 2; 151 women (44.4\%) used condoms whereas only 32 women (9.4\%) used OCP.The patients without a pregnancy plan (9.7\%) didn't use a contraceptive method and $22.9 \%$ of women without a pregnancy plan used interrupted coitus. One hundred seventy-eight (55.1\%) women out of 323 women who did not use any contraceptive methods commented on the reason; main

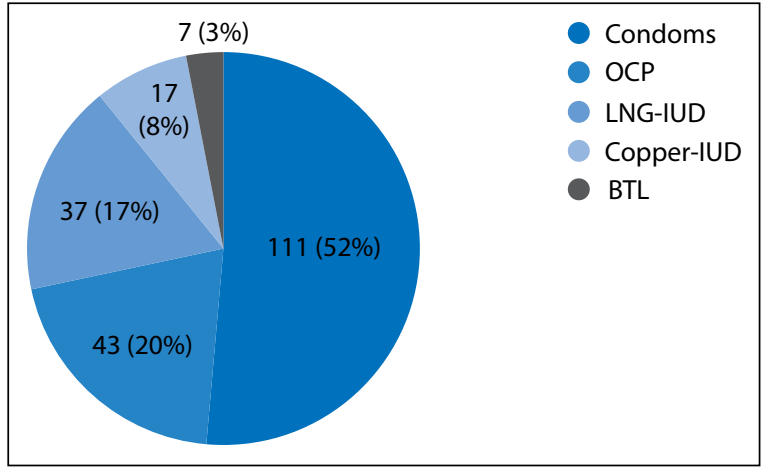

Figure 4. Distribution of the accepted contraception methods by the women who were convinced to use contraception after counselling $(n=215)$

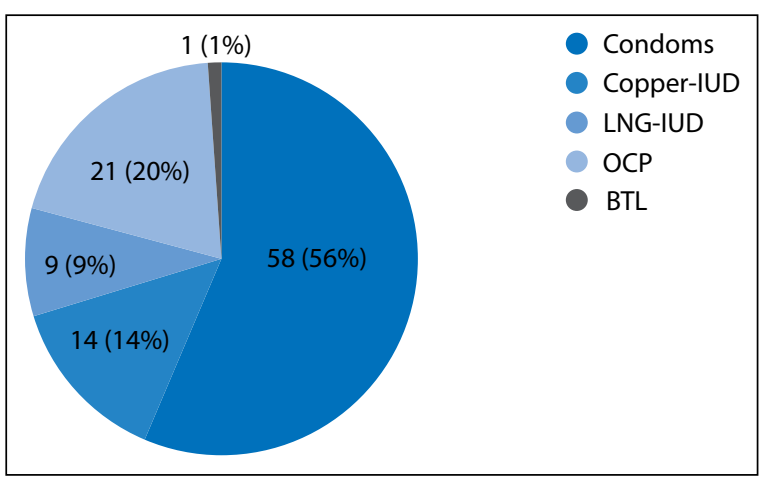

Figure 5. Distribution of accepted contraception method by the women who had used interrupted coitus before counselling $(n=103)$

reasons were concern for side effects $(n=39)$, absence of a partner $(n=36)$, pregnancy plan $(n=82)$, difficulty of use $(n=10)$, and other reasons $(n=11)$.

Two hundred seventy-nine women (35.9\%) had used OCP before, 177 (63.4\%) had used OCP for contraception whereas 102 women (36.6\%) due to physicians' prescriptions. Mean duration of usage was $23.8 \pm 39.4$ months. One hundred nineteen (42.7\%) women had used OCP for less than 6 months. The majority of short-term users used OCP for medical reasons whereas most long-term users used for contraception. Reasons for ending OCP usage are summarized in Figure 3.

Among 438 women who did not use modern contraception or used interrupted coitus or calendar method for contraception, 115 women were planning pregnancy and 323 women remained who didn't use modern contraception and didn't desire a pregnancy. Also, 215 of the 323 women $(66.5 \%)$ were convinced to use contraception. Contraceptive methods preferred by women after physician counselling are summarized in Figure 4. In addition, 103 (91.9\%) among 112 women who used interrupted coitus for contraception were convinced to use modern contraception. Results are summarized in Figure 5. On the other hand, Copper-IUD was 
switched to LNG-IUD in 24 women due to heavy menstrual bleeding.

When factors influencing the preferred contraception method were analyzed, there were significant relationships between age $(p<0.001)$, education level $(p=0.017)$, working state $(p=0.016)$, parity $(p<0.001)$, number $(p<0.001)$ and type of delivery $(p<0.001)$, previous OCP usage $(p=0.001)$, resources of contraception information $(p=0.006)$ and the preferred contraception method. Women who chose OCP were significantly younger than the women in the other groups ( $p<0.001$ ). Women over 40 years of age did not prefer to use OCP, but rather preferred IUD insertion. Most of the working women preferred OCP $(p=0.016)$. Women who chose OCP had a higher education level when compared to the women in the other groups $(p=0.017)$. Women who preferred BTL had higher number of children $(p<0.001)$. Most of the nulliparous women chose condoms and OCP. Nulliparous women did not prefer to use IUD; $97 \%$ of the women who chose IUD insertion were parous. Only 5 nulliparous women chose LNG-IUD insertion. More women who underwent BTL had a history of cesarean section when compared to other groups $(p<0.001)$. More women in the Copper-IUD and LNG-IUD groups had received information about contraception from physicians $(p=0.006)$. More women who chose condoms had received information from the web or their partners.

\section{DISCUSSION}

Due to high rate of unintended pregnancies, contraception counselling is crucial [23]. Time must be devoted to effective contraception counselling or other means should be provided in order to increase the efficacy especially in crowded outpatient clinics [24]. The World Health Organization (WHO) recommends that lifestyle issues and patient preferences should be considered when choosing the most appropriate contraception method for the women [21].

In our study, we showed that majority of women could effectively fill out the questionnaire by themselves and the physicians gave appropriate counselling to these women; only 30 women were not given effective counselling or counselling was not documented. After appropriate and individualized counselling, most of the women who used traditional contraceptive methods or did not use any method at all were convinced to use modern contraceptive methods.

This result is especially important considering the high number of primary school graduates in our study. Education level was highest in younger women aged 15-24 years. Caetano et al suggested that rates of unintended pregnancies were higher among younger women despite higher education level, which may be associated with inconsistent use of oral contraceptives [25]. In addition, $36.8 \%$ of the women were working in our study. As women's role in the society increases, contraception and planned timing of pregnancy becomes more important. In addition, busy schedules and life stressors may lead to inconsistent use of contraception and in these cases contraceptive counselling should include discussion of any potential barriers to adherence [25].

Most women in our study had received information about contraception previously. The main source of information was the physicians. In the TANCO study, 82\% of the women stated that their healthcare provider was the most important person for contraception counselling compared with just $10 \%$ stating that their partner was the most important person [26]. Physician's role remains quite important in contraception counselling; physicians may direct women to individualized contraception methods according to women's preferences and needs. Therefore, incorporation of contraception counselling to daily practice of gynecologists is essential even when the women's gynecologist visits involve other problems. Dehlendorf et al evaluated a patient-centered decision support tool for contraception counselling [27]. Patients used this tablet-based decision support tool prior to family planning visit and contraceptive continuation, method of use, satisfaction, and unintended pregnancy were evaluated. Authors concluded that the method had no effect on contraception continuity, but increased experience of contraceptive counselling and informed decision-making. A recent systematic review of patient preferences for contraceptive counselling found that women value comprehensive education about methods, with a emphasis on education about side effects [28, 29]. Kahramanoglu et al. [15] evaluated women's choices about contraception before and after gynecologist counselling. Physicians and health care providers were the best source for information about contraception. Partner input also had an impact on contraceptive choice. Religious beliefs may affect choice of BTL. Authors also suggested that hardest prejudices to overcome were anxiety of insertion and removal of an IUD, fear of weight gain from OCP usage, religious beliefs in case of BTL. Influences from social media and/or friend were found to be important factors in determining choice of contraception method as well.

Most women in our study preferred condoms, followed by IUD. The rate of OCP usage for contraception is quite low in Turkey when compared to other developed countries. Indeed, $35 \%$ of women in our study had used OCP, but only $11 \%$ of women were using OCP at the time being. Most had used OCP for short periods. Main reasons for stopping other than pregnancy plan were side effects and switching to another contraception method. After counselling by using the questionnaire, the number of women preferring to use OCP increased. This emphasizes the importance of counselling in OCP usage and individualization of treatment in order to prevent side effects. 
The majority of women using modern contraception preferred long-acting contraception. In the TANCO study involving 1089 physicians and 18521 women, $61 \%$ of the women were using oral contraceptives and only $9 \%$ were using long-acting contraceptive methods [26]. However $60 \%$ of the women stated that long-term contraception would be an option for them if they had received more information about it. In the Contraceptive CHOICE project, among 7637 women, $47 \%$ chose intrauterine systems whereas only $12 \%$ preferred OCP [30]. Cultural influences also affect the choice of contraception method.

Erfani and Yuksel-Kaptanoglu evaluated withdrawal method use in Iran and Turkey [31]. Lower education, poverty, having more than four children, and older age were associated with withdrawal use in Turkey. Authors suggested that family planning and reproductive health programs in Iran and Turkey should be aware of groups that have high rates of withdrawal and should encourage more effective contraceptive methods. Indeed, in our study $66.5 \%$ of women who did not use contraception and $83.5 \%$ of women who used interrupted coitus for contraception but didn't desire a pregnancy were convinced to use an effective method after contraception counselling with Contraception Counselling Form.

BTL has been a popular contraception method in Turkey. Forty-six women had undergone BTL and 7 women were convinced to undergo BTL in this study. The popularity of BTL is mostly due to high Cesarean section rates in Turkey and BTL is performed during Cesarean section when partners prefer. Laparoscopic BTL is also sometimes desired. In our study, we have shown that women may prefer laparoscopic BTL when they desire permanent contraception and are informed about the procedure. Eskicioglu et al evaluated regret state in women following BTL [32]. The rate of regret was 12-15\%. Factors associated with regret were young age (age $<30$ ), absence of spouse's support, not understanding permanent nature of procedure, lower education level, and thought of inability to have children in the future. Therefore, women and their partners must be thoroughly informed about nature of the procedure and misbelieved side effects in order to decrease rate of regret.

None of the couples used vasectomy in our study. Kısa et al, showed that more than $88 \%$ of Turkish men were not willing to have vasectomy and $35.4 \%$ thought that vasectomy had negative effect on marriage and health [33]. Sociocultural factors and misconceptions about vasectomy were main barriers for vasectomy use in Turkey.

In conclusion, contraception counselling using a questionnaire may aid in asking questions regarding method used or future use even if patients had come for other reasons to outpatient clinic and helps women to choose the best method. When considering that physicians were the most common source of information in our study, contra- ception counselling given to $97 \%$ of women applying for other reasons has been a success. Limitations of our study are lack of follow-up to evaluate usage of the preferred method, non-randomized nature of study, and lack of a control group. Education of women and adolescents regarding contraception, involvement of partners in counselling and support of all contraception methods by health insurance may aid in providing the most appropriate contraception. Contraception counselling using a questionnaire is an effective strategy to increase awareness about contraception both in women and physicians and to discuss about misconceptions aroused by society and social media about side effects.

\section{Acknowledgement}

Authors would like to thank Bayer Pharmaceuticals and Ilker Karabat for their support in the research and to Ms. Margaret Gillespie for the linguistic revision of the manuscript.

\section{REFERENCES}

1. Hubacher D, Trussell J. A definition of modern contraceptive methods. Contraception. 2015; 92(5): 420-421, doi: 10.1016/j.contraception.2015.08.008, indexed in Pubmed: 26276245.

2. American College of Obstetricians and Gynecologists' Committee on Health Care for Underserved Women. Committee Opinion No. 654 Summary: Reproductive Life Planning to Reduce Unintended Pregnancy. Obstet Gynecol. 2016; 127(2): 415, doi: 10.1097/AOG.0000000000001307, indexed in Pubmed: 26942382.

3. Ong J, Temple-Smith M, Wong WCW, et al. Contraception matters: indicators of poor usage of contraception in sexually active women attending family planning clinics in Victoria, Australia. BMC Public Health. 2012; 12: 1108, doi: 10.1 186/1471-2458-12-1108, indexed in Pubmed: 23259407.

4. Finer LB, Zolna MR. Declines in Unintended Pregnancy in the United States, 2008-2011. N Engl J Med. 2016; 374(9): 843-852, doi: 10.1056/NEJMsa1506575, indexed in Pubmed: 26962904.

5. Committee on Health Care for Underserved Women. Committee opinion no. 615: Access to contraception. Obstet Gynecol. 2015; 125(1): 250-255, doi: 10.1097/01.AOG.0000459866.14114.33, indexed in Pubmed: 25560140.

6. Donnelly KZ, Foster TC, Thompson R. What matters most? The content and concordance of patients' and providers' information priorities for contraceptive decision making. Contraception. 2014; 90(3): 280-287, doi: 10.1016/j.contraception.2014.04.012, indexed in Pubmed: 24863169.

7. United Nations, Department of Economic and Social Affairs, Population Division . Trends in Contraceptive Use Worldwide. 2015; 2016.

8. Caetano C, Peers T, Papadopoulos L, et al. Millennials and contraception: why do they forget? An international survey exploring the impact of lifestyles and stress levels on adherence to a daily contraceptive regimen. Eur J Contracept Reprod Health Care. 2019; 24(1): 30-38, doi: 10.1080/13625187.2018.1563065, indexed in Pubmed: 30689459.

9. Frost JJ, Darroch JE. Factors associated with contraceptive choice and inconsistent method use, United States, 2004. Perspect Sex Reprod Health. 2008; 40(2): 94-104, doi: 10.1363/4009408, indexed in Pubmed: 18577142.

10. ESHRE Capri Workshop Group. Why after 50 years of effective contraception do we still have unintended pregnancy? A European perspective. Hum Reprod. 2018; 33(5): 777-783, doi: 10.1093/humrep/dey089, indexed in Pubmed: 29659848.

11. Sedlecky K, Rašević $M$, Bitzer J. Education and training of health care workers for contraceptive service delivery in 21 countries across Europe. Sex Reprod Healthc. 2020; 24: 100498, doi: 10.1016/j.srhc.2020.100498, indexed in Pubmed: 32078986.

12. Alkema L, Kantorova V, Menozzi C, et al. National, regional, and global rates and trends in contraceptive prevalence and unmet need for family planning between 1990 and 2015: a systematic and comprehensive analysis. Lancet. 2013; 381(9878): 1642-1652, doi: 10.1016/S01406736(12)62204-1, indexed in Pubmed: 23489750. 
13. Cahill N, Sonneveldt E, Stover J, et al. Modern contraceptive use, unmet need, and demand satisfied among women of reproductive age who are married or in a union in the focus countries of the Family Planning 2020 initiative: a systematic analysis using the Family Planning Estimation Tool. Lancet. 2018; 391(10123): 870-882, doi: 10.1016/S0140-6736(17)331045, indexed in Pubmed: 29217374.

14. Çağatay Seçkiner $P$, Akadlı Ergöçmen B, Abbasoğlu Özgören A. Aile Planlaması. Hacettepe Universitesi Nufus Etutleri Enstitusu (HUNEE) Turkiye Nufus ve Saglik Arastirmasi. T.C. Kalkinma Bakanligi ve TUBITAK, Publication No. NEE-HÜ.09. 01 ISBN 978-975-491-274-6 Ankara, Türkiye. ; 2013.

15. Kahramanoglu I, Baktiroglu M, Turan $\mathrm{H}$, et al. What influences women's contraceptive choice? A cross-sectional study from Turkey. Ginekol Pol. 2017; 88(12): 639-646, doi: 10.5603/GP.a2017.0115, indexed in Pubmed: 29303220.

16. Chin-Quee DS, Janowitz B, Otterness C. Counseling tools alone do not improve method continuation: further evidence from the decision-making tool for family planning clients and providers in Nicaragua. Contraception. 2007; 76(5):377-382, doi: 10.1016/j.contraception.2007.07.003, indexed in Pubmed: 17963863.

17. Schunmann C, Glasier A. Specialist contraceptive counselling and provision after termination of pregnancy improves uptake of long-acting methods but does not prevent repeat abortion: a randomized trial. Hum Reprod. 2006; 21(9): 2296-2303, doi: 10.1093/humrep/del168, indexed in Pubmed: 16751644.

18. Langston AM, Rosario L, Westhoff CL. Structured contraceptive counseling--a randomized controlled trial. Patient Educ Couns. 2010; 81(3): 362-367, doi: 10.1016/j.pec.2010.08.006, indexed in Pubmed: 20869187.

19. Nobili MP, Piergrossi S, Brusati V, et al. The effect of patient-centered contraceptive counseling in women who undergo a voluntary termination of pregnancy. Patient Educ Couns. 2007; 65(3): 361-368, doi: 10.1016/j. pec.2006.09.004, indexed in Pubmed: 17125957.

20. Dehlendorf C, Kimport K, Levy K, et al. A qualitative analysis of approaches to contraceptive counseling. Perspect Sex Reprod Health. 2014; 46(4): 233-240, doi: 10.1363/46e2114, indexed in Pubmed: 25040686.

21. WHO Medical Eligibility Criteria for Contraception Use, 5th Edition, 2015, ISBN: 978. ; 92: 4.

22. Committee on Gynecologic Practice Long-Acting Reversible Contraception Working Group. Committee Opinion No.642: Increasing access to contraceptive implants and intrauterine devices to reduce unintended pregnancy. Obstet Gynecol. 2015; 126(4): e44-8.
23. Erol N, Durusoy R, Ergin l, et al. Unintended pregnancy and prenatal care: a study from a maternity hospital in Turkey. Eur J Contracept Reprod Health Care. 2010; 15(4): 290-300, doi: 10.3109/13625187.2010.500424, indexed in Pubmed: 20809676.

24. Dehlendorf C, Levy K, Kelley A, et al. Women's preferences for contraceptive counseling and decision making. Contraception. 2013; 88(2): 250-256, doi: 10.1016/j.contraception.2012.10.012, indexed in Pubmed: 23177265.

25. Caetano C, Peers T, Papadopoulos $L$, et al. Millennials and contraception: why do they forget? An international survey exploring the impact of lifestyles and stress levels on adherence to a daily contraceptive regimen. Eur J Contracept Reprod Health Care. 2019; 24(1): 30-38, doi: 10.1080/13625187.2018.1563065, indexed in Pubmed: 30689459.

26. Oppelt PG, Baier F, Fahlbusch C, et al. What do patients want to know about contraception and which method would they prefer? Arch Gynecol Obstet. 2017; 295(6): 1483-1491, doi: 10.1007/s00404-017-4373-1, indexed in Pubmed: 28434106.

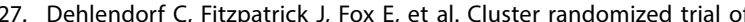
a patient-centered contraceptive decision support tool, My Birth Control. Am J Obstet Gynecol. 2019; 220(6): 565.e1-565.e12, doi: 10.1016/j. ajog.2019.02.015, indexed in Pubmed: 30763545.

28. Fox E, Reyna A, Malcolm NM, et al. Client Preferences for Contraceptive Counseling: A Systematic Review. Am J Prev Med. 2018; 55(5): 691-702, doi: 10.1016/j.amepre.2018.06.006, indexed in Pubmed: 30342632.

29. Dehlendorf C, Fox E, Sobel L, et al. Patient-Centered Contraceptive Counseling: Evidence to Inform Practice. Current Obstetrics and Gynecology Reports. 2016; 5(1): 55-63, doi: 10.1007/s13669-016-0139-1.

30. Secura GM, Allsworth JE, Madden T, et al. The Contraceptive CHOICE Project: reducing barriers to long-acting reversible contraception. Am J Obstet Gynecol. 2010; 203(2): 115.e1-115.e7, doi: 10.1016/j. ajog.2010.04.017, indexed in Pubmed: 20541171.

31. Erfani A, Yuksel-Kaptanoglu I. The use of withdrawal among birth limiters in Iran and Turkey. Stud Fam Plann. 2012; 43(1): 21-32, doi: 10.1111/j.17 28-4465.2012.00299.x, indexed in Pubmed: 23185869.

32. Eskicioglu F, Gur EB, Tatar S, et al. The evaluation of regret status in women following tubal ligation in Turkey. Clin Exp Obstet Gynecol. 2017; 44(1): 93-97, indexed in Pubmed: 29714874.

33. Kısa S, Savaș E, Zeyneloğlu S, et al. Opinions and Attitudes About Vasectomy of Married Couples Living in Turkey. Am J Mens Health. 2017; 11(3): 531-541, doi: 10.1177/1557988315620275, indexed in Pubmed: 26634860. 